\title{
Research through action: research protocol on the implementation of an integrated place-based primary intervention in a multicultural context.
}

Lara Maillet ( $\sim$ lara.maillet@enap.ca )

ENAP

Manceau, Luiza Maria

Université de Sherbrooke

France Desjardins

Université de Sherbrooke

Suzanne Gagnon

Université Laval

Lavanyah Naraziah

Université de Montréal

Sabina Abou Malham

Université de Sherbrooke

\section{Method Article}

Keywords: immigration, healthcare system, adaptation, medical access, equity, Canada, Quebec, adaptation, research action, collaboration

Posted Date: March 8th, 2022

DOI: https://doi.org/10.21203/rs.3.rs-1390041/v3

License: (9) This work is licensed under a Creative Commons Attribution 4.0 International License. Read Full License 


\section{Abstract}

Our project specifically aims at improving the adaptation capacity of primary services to answer the complex needs of vulnerable people. The aim is to co-build, with our collaborators and partners, environment-based strategies enabling the coordination of primary services offered by health, social and community responders all the while ensuring the continuity of care (informational, relational, and contact) of vulnerable people, especially refugees. A particular attention is brought toward the experiential knowledge of the health system users. Therefore at least three citizen-partners are part of the research team since the beginning of the project.

Goals: This research-action aims at implementing a "meshing innovation", meaning an intervention that is integrated, lasting, and based on the needs of a community located in a Sherbrooke neighbourhood in order to improve the care of refugee people in a continuum of primary services. To reach this goal, we have 5 specific objectives.

The overall goal of this project is to improve the services trajectory in the health and social services network for refugee people in Quebec. The implementation of a meshing innovation, through this pilot project, is a first step toward this overall goal.

Method: This project falls within a participative research approach, based on the symmetry principle of the researchers and field stakeholders' knowledge. To do so, we choose three distinct sources of data: (1) literature review, (2) focus group ( $N=9$ twice), and (3) semi-structured interviews $(\mathrm{N}=10)$.

Expected results: Concretely, an Implementation guide of establishment strategies for integrated interventions enabling the improvement of primary care for refugees will be written and will constitute the basis for an appropriation workshop for the members of the two joint research networks focused on primary practices (RRAPPL) (Université de Laval and Université de Sherbrooke) and, eventually, in other fields interested in adapting and implementing these strategies. In addition to this guide, we wish to facilitate the care of refugees by family practitioners of the territory; therefore, many of them are part of the project. Explicit ties will help raising awareness toward other family practitioners working in medical clinics of the territory while trying to facilitate a specific attribution to these practitioners through the Quebec Family Doctor Finder (GAMF). With this project, we strongly hope to promote the vulnerability factors of refugees to the Health and Social Services Department (MSSS) and to the Quebec General Practitioners Federation (FMOQ) to change the priority at the GAMF. Finally, a scientific publication will be written for an international journal.

\section{Introduction}

Important Needs for Primary Services 
Many responders, clinicians and decision-makers of the studied territory told us about the needs underlying this project. According to them, if ties exist between the services offered to refugees following their visit in clinics for refugees (CdR), there is also a lack of coordination, integration and continuity between the stakeholders of the various sectors involved (e.g., social, sanitary, housing, education and municipal). Yet, the silos between these sectors are obstacles to the implementation of intersectoral actions essential for global and efficient care for refugees living in a situation of vulnerability[1]. It is, however, proved that to fight social inequalities and act on the health's social determinants, an active approach based on the local needs allows accompanying, supporting and implementing services conceived by, for and with the concerned people (1-4). Moreover, strategies based on an offer of coordinated and continuous services help improving primary interventions for these vulnerable populations and encouraging their integration (5). To encourage a continuity of services for refugees after their visit at the $C d R$, this project is grounded on place-based strategies (6), which will allow building a bridge between health, social and community services.

\section{Aiming at changing practices}

This type of action will allow refugees to be cared for in a continuum of care and place-based services in the community they belong to. The project proposed is consistent with the 4 priorities of Réseau-1 Québec[2], being:

1. Participation of refugees and/or migrant people as research partners from the beginning of the project.

2. Improvement of communication and information sharing.

3. Optimization of the services trajectories.

4. The services' capacity to answer in an adequate and adapted manner to the complex needs of this type of clientele.

[1] Vulnerability is understood here according to Pampalon's index, being material and social disadvantages. The juxtaposition of these dimensions increases the risks of insecurity and exclusion (OEDC, s.d.).

[2] Réseau-1 Québec is a knowledge network of integrated primary health and care services. It is founded on an infrastructure of member clinics attached to one of the four RRAPPL (Research Network Focused on Primary Practices) that covers the Quebec territory. Each RRAPPL is under the responsibility of a department of family practice and emergency medicine of Laval University, McGill University, Montreal University or Sherbrooke University.

\section{Literature Review And Problematic}


Important social health inequalities have been observed between various social groups in Quebec and elsewhere (8-11). They're actually gaps in socially stratified health statuses (12). These gaps affect a lot of various health indexes (from risk factors to care results) and reproduce, in the health and social services sectors, the existing inequalities between social groups (12). This means that some groups in a "vulnerable health and social situation" are "at a higher risk level" than others because they share social characteristics $(9,12-14)$. According to Link and Phelan (15), the risk factors and their accumulation are the expression of the fundamental causes related to the position of a group or an individual within the social structure. These causes are the risks that lead to the exposition to other risks (e.g., having a weak socio-economic status, being of aboriginal descent, having a low level of education, etc.) (15).

Some characteristics, such as socio-economic precariousness, exposition to violence, experience of isolation and/or family separation, language barriers, mental health issues as well as pathologies specific to some regions and cultures in the world affect migrant people[1] and more especially refugees[2] during the first post-migration years $(17,18)$. Hence, the health and well-being status of these people is very fragile $(19,20)$, due to their living conditions in their origin country or in the countries through which they transited, but also due to hardships related to their integration in the host society (21). They are at high risk for certain health issues such as infectious diseases (e.g., tuberculosis, malaria, other parasite infections, hepatitis B), chronicle diseases (e.g., cardiovascular diseases, lung disorders, diabetes) and psychosocial and mental health issues (e.g. depression, post-traumatic stress disorders) (22).

\section{Populations Who Are Underserved by the Health System}

Not only migrant people are part of the groups of people who have numerous unanswered needs, meaning "a situation in which a person perceives or feel the need to obtain health services without obtaining them" (23) in the host society, but they also are the most underserved by the health system and its professionals. Numerous studies related to the access to primary health and social services support this statement and argue that migrant people experience difficulties to obtain necessary care; receive fewer services; receive services of inferior quality; are treated differently by care providers; receive a treatment that doesn't match their needs $(13,24,25)$.

Concerning the studied region, a report led by the public health direction (2016) meets some of these statements. The results of three focus groups conducted with 27 immigrants from the two main towns of the region underline the difficulty of accessing health and social services, including the access to mental health services that are culturally appropriated (26). They also mention cultural barriers associated with 
different perceptions of health, that of the immigrant and that of the host environment; difficulty of obtaining the requested information and understanding it; the necessity to develop the cultural abilities of the health network and social services personnel to interact with the immigrant community (26).

Few regional data concerning the access to primary health and social services for refugees are currently available.

Role of the health system and the social services to encourage primary and secondary access to the health and social services for refugees

Although the majority of research reveal that the great health disparities come from determinants located outside of the health system, it must be said that the latter, through the inequalities of care resulting from the difficulty of primary and secondary access can contribute to increasing these disparities $(37,45,46)$. The World Health Organization argues that the interruption in the continuum of services for migrant people constitutes a major problem that reinforces their vulnerability, due to the lack of access to the health system and to care providers, or to the limited number of services offered (47). Ensuring the accessibility of primary services to people in situations of social and health vulnerability to contribute to health equity is currently a public health priority, at the regional $(48)$, national $(11,49,50)$ and international (11) level. Even if it is known that the health systems, and its professionals, must contribute to establishing health equity $(11,12,22,51)$, there are no easy solutions. They have been confronted to important challenges in the elaboration, development and implementation of appropriated and relevant interventions helping to overcome the obstacles faced by migrant people (including refugees) and thus encouraging primary and secondary access to health services and social services $(22,52)$.

In Quebec, while the regional program for the reception and integration of asylum seekers was gaining dozens of years of experience, clinics for refugees (CdR) emerged in 2007 in order to evaluate the wellbeing and the physical health status of refugees or asylum seekers at their arrival (21). These clinics, including one located in Sherbrooke since 2009, fall within the orientation's framework of the MSSS regarding the health of refugees (53). They offer adapted primary health services and social services; an anchor to ensure a better start in their new living environment (54). In Sherbrooke, the CdR is only accessible with a reference from the welcome organizations for refugees, being the Support Service for New Canadians (or SANC), Transcultural Education Association (or AET) and the Syriac Church of Sherbrooke (54). 
Even though the CdRs offer a first access to the health system, they do not aim at ensuring the continuity of services $(53,54)$, a component defining secondary access (28). This component involves the seamless transition between various services at the same level, at different levels and between different organizations (55).

Indeed, the mandate of the $\mathrm{CdR}$ is to offer a global evaluation (i.e. a physical health and psychosocial well-being overview), a punctual treatment and references within the health network and the social services depending on the needs of refugees. These references are made with: the GAMF; a university hospital center (CHUS) (if an appointment with a medical specialist is necessary); chronicle diseases, psychology and psychosocial services; community organizations; dentists; optometrists (54).

Thus, during their visit to the $\mathrm{CdR}$, refugees meet the nurse, the practitioner, the social worker and if need be, the nutritionist. At that moment and in the following months, many intersectoral collaborations happen with various community partners (e.g. district interventions, welcome centers, schools, etc.). However, after that visit, refugees must go through the general health network and face the obstacles mentioned previously.

Access to walk-in clinics is very difficult for Allophone people (or who don't speak either French or English); the only choice left being going to the emergencies for minor issues. Given that no vulnerability factors are recognized on being a refugee, the access to care by a family practitioner is not advantaged (56).

Finally, it must be shown that the complexity of issues presented by some refugees calls for skills and knowledge. Many situations require an intersectoral, adapted and global approach (56).

Given that the care and follow-up of refugees is not secured, it becomes difficult for them to navigate between the medical, social and community services of their new living environment (52). Consequently, it becomes crucial to develop mechanisms ensuring a better coordination and adaptation of services in order to allow for continuity and for a better answer to the needs of this type of population.

As an example, these mechanisms could help: 
- Facilitating the care of refugees in order to ensure a post-CdR continuity and that between the different episodes of care and social interventions required within the health and social services networks;

- Accompanying and supporting the refugees in navigating the health and social services, meaning the access, appointment-making and coordination and follow-up if need be;

- Defining and implementing mechanisms for the referral and transfer of users between the service providers, including the community partners;

- Establishing the process, implementing mechanisms or making agreements with the various service providers, which specify the mutual responsibilities in order to rely on intersectoriality and to improve the continuity of services depending on the conjointly targeted results $(55,57)$.

[1] The term « migrant person » relates to any individual who is born outside of Canada but who lives there whatever the migration trajectory might be. This can include refugees, people waiting for a status, undocumented people, asylum seekers, economic migrants and family reunification.

[2] According to the Geneva Convention, a « refugee » matches all the following criteria: 1) Someone who is outside of his/her citizenship country or, if he/she doesn't have the citizenship, where he/she usually lives; 2) Someone who rightfully fears to be persecuted due to his/her race, religion, nationality, affiliation to a social group or political opinions; 3 ) Due to this fear, this person cannot or doesn't want to claim protection from this country or go back to this country (16).

\section{Methodology}

Our project will fall within a participative research approach, based on the symmetry principle of the researchers and field stakeholders' knowledge. It will truly be about co-building knowledge. The partners are associated with all the steps of the project. Our research method is presented as follows.

Our quote is built as a participative action research, meaning a "methodological practice centered on the resolution of a concrete problem experienced in a real situation in order to bring beneficial change to it, to contribute to the personal development of the people who take part in it and to improve the knowledge on that situation"[1]. Research through action is thus part of a cycle of production and use of knowledge that is scientific and implicit on the problematic we focus on. That is why our research team is made of researchers, practitioners-researchers, community responders and citizen-partners (Ref. Research team). A follow-up committee will facilitate the intersectoral correspondence and the diffusion of results. Two RRAPPL are called upon, which encourages the synergy and progress of the project. Networking will help establishing efficient and fast communication strategies between the members of the two RRAPPL. The aim is to transfer this pilot project to other contexts, including that of Quebec City. 
The long-term goal, and within a larger scaled research project, is to expand this meshing innovation to the Quebec CdR and all of the province's CdR $(\mathrm{N}=13)$.

Data collection: The qualitative method will combine documentary sources, semi-structured interviews and focus groups on refugees of the targeted environment for this research, responders, managers and stakeholders of the community (Obj. $\mathbf{1}$ to $\mathbf{3}$ ).

In addition to the literature review, a documentary analysis of available literature (e.g. policies, task description, management agreement, report, etc.) concerning the health, social and community services accessible to refugees in Quebec will be carried out. Moreover, the documents specifically related to the functioning, the mandate, and the tasks of the CdRs will be analyzed. This collected data will be used to better contextualize the project.

A researcher or possibly a student, in person or on the phone, will conduct the semi-structured interviews with responders, professionals and managers; key stakeholders involved in the health, social and community services offer. The selection of the key informants will be based on two methods: 1) rational choice (depending on the implication in these services) and 2) "snowballing". We estimate more or less ten interviews ( $\mathrm{N}=+/-10)$ (Obj. 1 to 3 ).

Moreover, six (6) focus groups will be conducted in order to answer to objectives $\mathbf{1}$ to $\mathbf{3}$ of the research:

- Two focus groups (2) with refugees in Sherbrooke, who have used the services offered by the CdR and the residents of the Des Jardins Fleuris neighbourhood.

Each of the focus group will have 8 to 12 people maximum. There will be a focus group for men and one for women in order to encourage discussion and limit the effects of power related to gender.

- One focus group (1) with responders/professionals working directly with refugees. 
- One focus group (1) with the managers involved in programs and executive management of the CIUSS de l'Estrie CHUS responsible for the care and services offered to refugees.

- One focus group(1) with the regional medical policy-makers and leaders who can take charge of or act on the decisions concerning the organization of primary medical services of the territory.

- One focus group(1) with the stakeholders of the community sector and the partners involved or who are working with refugees and collaborate with the social and health services.

To carry them out, a researcher, a citizen-partner of the team and possibly a student will moderate these focus groups that will last from 120 to 180 minutes. Indeed, using the technique of "drawinginterviewing" for the focus group with refugees, it is important to take the time necessary, meaning 180 minutes or 3 hours per group.

The drawing-interviewing technique is preferred because it holds many advantages during focus groups with minority cultural groups (64). This technique is achieved by following a 4-step process: 1) individual drawing, 2) individual presentation, 3) collective drawing and 4) collective pre-analysis. Among the qualities of this technique is the establishment of a respectful, convivial climate that doesn't feel artificial. The first step encourages interiority through a moment of silence and reflection. Combining drawing and group discussion also encourages the balance of participation of all the participants (more or less comfortable or familiar with the spoken language in the focus group, being English or French). Lastly, this technique encourages a more direct communication with Allophone people or those who are less comfortable in English or French (64).

For the 4 other focus groups, the traditional discussion technique will be maintained, which will reduce the meeting time to 2 hours maximum. The groups will also be composed of 8 to 12 people maximum in order to maintain a group dynamic and facilitate discussion and exchanges. Moreover, we have divided the groups in order to avoid unequal hierarchical dynamics.

During the semi-structured interviews and focus groups, an information sheet will be given to all of the participants in order to compile all the socio-demographic data (Annex E. Information sheet). 
Following the analysis, the research team and the follow-up committee will target the most promising strategy to develop and implement (Obj. 3). This choice will be based particularly on the answer to the needs expressed during the focus groups, the data standing out of the literature and its feasibility as a pilot project within the allocated time. We will look for a consensus for all of these criteria (and others could add up).

The implementation of a meshing innovation will first unravel in Sherbrooke, in the Des Jardins Fleuris neighbourhood where place-based social services exist through the Intervention de Quartiers program $(65,66)$.

This neighbourhood is selected for many reasons. In addition to being the neighbourhood that belongs to the $\mathrm{CdR}$, it represents one of the most underprivileged neighbourhoods of Sherbrooke (highest proportion of people living under the low-income cut-off), where more than one out of ten people don't speak French, and where 1 out of 10 people is a recent immigrant (67). It's a multiethnic neighbourhood, gathering a large part of the refugee population coming from Afghanistan, for example. The community organizations are very active here.

In a second phase (other grant), the implementation may be adapted to other environments (e.g. Granby, Quebec City and Brossard). The practitioners and managers responsible for these CdRs are involved in every step of the project.

Moreover, through the analysis of these various focus groups, we would like to bring out strategies encouraging the improvement of access and trajectories of refugees through the health network and social services in a general manner and not only centered on the territory of Des Jardins Fleuris.

Before answering objective 4, and following the implementation of the meshing innovation that emerged from the previous analysis, three focus groups will be carried out with refugees and responders in the targeted neighbourhood for the intervention in order to collect their perception on the changes made or not. Whenever possible, we will ask people of the previous focus groups to participate. The drawinginterviewing technique will be used once again in order to grasp the changes experienced since the previous interview: Will the implementation of the meshing innovation have an impact on their experiences as users and/or responders? 
Finally, objective 5 will be achieved thanks to the systematic follow-up on the whole process of the project since the beginning (e.g. keeping a logbook, agendas and summaries of the team meetings and of the committee as well as of the exchanges with the Réseau-1 Québec committee). In addition to documenting the process of this pilot project, the realization of this objective will also allow for the transfer of experience to other contexts.

Data analysis: the interviews and the focus groups will be recorded and transcribed. The analysis will be led iteratively in teams (researchers, citizen-partners, students) and will include the successive reading of the verbatim and visual material (drawing-interviews), the codification and thematic analysis related to the analytical framework. The validation with the participants and the follow-up committee will follow.

The empirical material will be analyzed with the software QDA MINER (version 4.1.35) by combining various methods of which the most important are:

1) Thematic analysis, which consists in identifying and analyzing the themes "revealed" by the data. More precisely, we will choose an inductive and deductive approach, which allows the researchers to draw meaning by relying on the analytical framework and the state of knowledge, all the while being alert to new significations. There will be frequent back and forth between the analysis phases and the research team meetings. Moreover, the follow-up committee will be involved following the data analysis for each of the objectives.

2) The temporal bracketing strategy will aim at highlighting how the actions occurring at one step change the context that will influence the action of the actors at the following steps by dividing the processes into phases. This strategy will be used to follow, in real time, the development and implementation of the meshing innovation all the while retroactively analyzing the various steps leading to this innovation.

Validity of the study: Many strategies guarantee the credibility of the study: coherence between the objectives of the research and methods chosen, triangulation of various sources of data, iterative collecting and analysis process of the data, research of alternative data thanks to the validation of interpretations with the field actors and involvement of all the team members in the research process.

The transferability of our results, the capacity to draw meaning "elsewhere", rests on the following means: a sharp description of the context in order to better understand its influence and the elaboration of a more abstract interpretation of the phenomenon.

[1] Guay, M.-H, and Prud'homme, L. (2011). La recherche-action. In T. Karsenti and L. Savoie-Zajc (dir.). La recherche en éducation: étapes et approches, 3rd edition, (p. 183-211). Saint-Laurent: ERPI. 


\section{Ethics, Safety And Dissemination}

The protocol will be submitted for approval to the ethics committee of the CIUSSS de l'Estrie - CHUS (\#2018-2384). Out of respect for the various people concerned by this research, data collection and analysis emerging from the documentary collection, observations and individual interviews are submitted to the following ethical rules.

\subsection{Free and informed consent}

A particular attention will be brought to the information transmitted to the participants so that they can choose in a free and informed manner to participate in the process or not.

During recruitment, the lead researcher or the research professional will verify the eligibility of the people interested based on the inclusion requirements. They will introduce the evaluation to the eligible people by using the information in the invitation to participate that will be handed out. If the person accepts to participate, the lead researcher or the research professional will set up a meeting for the interview or the focus group. Pour les personnes réfugiées qui ne parlent pas français ou anglais, les tiers qui collaborent à leur recrutement vérifieront directement l'admissibilité de la personne intéressée à participer à partir des critères d'inclusion et confirmeront leur disponibilité à la date et l'heure prévue pour le focus group.

During recruitment, the lead researcher or the research professional will verify the eligibility of the people interested based on the inclusion requirements. They will introduce the evaluation to the eligible people by using the information in the invitation to participate that will be handed out. If the person accepts to participate, the lead researcher or the research professional will set up a meeting for the interview or the focus group. For the refugee people who do not speak French or English, the third party who will collaborate to their recruitment will directly check the eligibility of the interested person from their inclusion criteria and will confirm their availability at the date and time scheduled for the focus group.

Each individual semi-structured interview and each of the focus group will start by the reading of an information and consent form featuring all the information helping the participants understanding the object, risks, and potential benefits of the project and the implications of their participation. A time of reflection is planned for the participants to ask questions and confirm or not their participation to the study. The interviewer will answer questions, ask for written consent and will give a copy of the consent form to each of the participants before the interview/focus group as a proof of consent and participation. The interviews and focus groups will be recorded with their consent and the participants can stop whenever.

\subsection{Possible Benefits, Risks and Inconveniences Related to the Participation}


Participating to this research will give the participants an opportunity to reflect and exchange in all confidentiality on integrated, lasting interventions that are based on the needs of the community of a Sherbrooke neighbourhood in order to improve care within a continuum of primary services toward refugees. During the research-action, they will contribute to the development and implementation of meshing innovations within the community of Des Jardins Fleuris in Sherbrooke. In the end, they will contribute to the progress of knowledge on the initiatives helping the improvement of primary health care and social services continuity offered to refugee people.

No major risks are associated with participating in the research. However, it is possible that some participants feel uncomfortable being recorded or observed during the interview or regarding certain questions. If so, participants are free to ask that the recording be stopped and free not to answer the questions they deem embarrassing. It is also possible that some participants are worried by the use of the research data to other means than the one intended in the protocol. Through the consent form, the participants will be informed that their participation is not in any way an evaluation of their personal performances, but rather the documentation of a process on which no value judgment is brought to understand and improve the practices. The only disadvantage for the participants is the time dedicated to the individual interviews or the focus group.

No major risks are associated with participating in the research. However, it is possible that some participants feel uncomfortable being recorded or observed during the interview or regarding certain questions. If so, participants are free to ask that the recording be stopped and free not to answer the questions they deem embarrassing. It is also possible that some participants are worried by the use of the research data to other means than the one intended in the protocol. Through the consent form, the participants will be informed that their participation is not in any way an evaluation of their personal performances, but rather the documentation of a process on which no value judgment is brought to understand and improve the practices. The only disadvantage for the participants is the time dedicated to the individual interviews or the focus group.

\subsection{Protection of private life and confidentiality}

The research professional and, if applicable, the students involved as well as the transcriber will commit to respect the confidentiality norms and ethical rules of this study with a written consent.

No information on the participation or information given by a participant will be shared without prior authorization, according to the terms described in the consent form. It is possible that a quote from a semi-directed individual interview or a focus group might be used to complement an important point of the analysis. However, no mention of the participant's name will follow the quote. Only the role of the quoted participant could be (ex.: user, responders, manager). 
The names of the participants will be replaced by an alias, every time possible during the recruitment and consent stages, collection, analysis, and diffusion of the results.

\subsection{Data storage and security}

The lead researcher or the research professional present during the interviews or observations will put the consent forms and written notes in an envelope identified by an alias on the data collection location, the day during which the data was collected.

The lead researcher will also store the personal data of participants that is necessary for recruitment (ex.: contact information), the sociodemographic information sheet and the consent form separately, in a locked binder located in a closed room.

The digital material of the research, being files and data, the code (Ref. to the alias), the transcriptions of interviews, notes and summaries as well as audio recordings will be stored on a secured server, accessible only to the system's administrators. This server is fitted with a firewall. Passwords will be created for the various files.

The lead research will have the responsibility to control the access to the material of the research-action.

All material and data of the research-action will be destroyed 5 years after the end of the research, in November 2022 at the latest by the lead researcher.

\section{Discussion And Expected Results}

The involvement of the stakeholders of the three CdRs from the beginning (Sherbrooke, Quebec City and Brossard) will facilitate the adaptation and the implementation of our intervention since the participative method used can be adapted and reproduce elsewhere. Developing an integrated intervention that is adapted to the environment with the participation of citizen-partners encourages the change of practices. According to Weiss, participating to a process produces change (or enlightenment) (68).

These changes experienced at the practice level invites the managers and decision-makers to consider a governance in primary care that allows more global and coordinated practices, especially during the care of vulnerable people such as refugees and, a broadening of the partnerships and the network surrounding the health facility, at the local, regional and national level. It is not a matter of creating a "social and health system for refugees" on the side, but rather defining the specificity of the problematic and bringing coherent solutions in order to support the adaptation of the activities and structures that are evolving in the current health and social services system (69). 
The follow-up indicators of the project will highlight the following principles: accessibility, continuity, reactivity and entirety (59) in order to take into consideration, the direct and indirect implications for refugee people (users), the responders and professionals, and the organization of services (58).

Concretely, we will elaborate an Implementation guide of establishment strategies for integrated interventions enabling the improvement of primary care for refugees. This guide will constitute the basis for an appropriation workshop for the members of the two RRAPPL partners (Université de Laval and Université de Sherbrooke) and eventually in other fields interested in adapting and implementing these strategies. The members of these RRAPPL, whether they are researchers, managers, practitioners, or citizen-partners, will be invited to this appropriation workshop. Moreover, we hope to use research day of Réseau-1 Québec in June 2018 to present and improve the implementation guide and connect with other sectors interested by this implementation.

In addition to this guide, we wish to facilitate the care of refugees by family practitioners of the territory; therefore, many of them are part of the project. Explicit ties will allow raising awareness toward other family practitioners working in medical clinics of the territory while trying to facilitate a specific attribution to these practitioners through the Quebec Family Doctor Finder (GAMF). Finally, we hope to publicize the vulnerability factors for refugees toward the MSSS and the FMOQ in order to change the priority at the GAMF.

Finally, a scientific publication will be written for an international journal.

Limits: The one-year period allows for the implementation of the initiative in only one Sherbrooke neighbourhood. It is, however, intended to develop and request larger funds to other granting organizations. This will facilitate a contextualized transposition of this type of innovative strategies to other CdR territories in Quebec following this project, in addition to securing an implementation evaluation for it. A pan-Canadian phase could also be added.

As mentioned above, there are possible limits in the execution of focus groups with refugee people coming from countries where women's status is not considered as the men's. This is why we choose to create two different groups in order to facilitate exchanges between participants and avoid discomfort or restraint with participants of the other sex. 
In the same manner, we make the ethical choice to hold focus groups where hierarchical levels within an establishment are separated (e.g. group of managers versus group of responders). We wish to facilitate exchanges and discussions all the while minimizing unequal power relationships between participants.

Finally, despite the forces and the will to act surrounding the research-action project, it will be important all along the process to maintain the relationships between the follow-up committee, the research partners and the research team. The lead researchers, with the help of the support committee of Réseau-1 Québec, will brief these various bodies regularly.

\section{References}

1. Baxter C, Levin R, Legaspi MM, Bailey BE, Brown CL. Community health center-led networks: cooperating to compete. J Healthc Manag Am Coll Healthc Exec. 2002 Dec;47(6):376-388; discussion 388-389.

2. Fielding JE, Teutsch SM. Integrating clinical care and community health: delivering health. JAMA. 2009 Jul 15;302(3):317-9.

3. N Touati, AP Contandriopoulos, JL Denis, R Rodriguez R, C Sicotte. Une expérience d'intégration des soins dans une zone rurale: les enjeux de la mise en oeuvre. Ruptures, revue transdisciplinaire en santé. 2001;8(2):93-108.

4. Khanassov V, Pluye P, Descoteaux S, Haggerty JL, Russell G, Gunn J, et al. Organizational interventions improving access to community-based primary health care for vulnerable populations: a scoping review. Int J Equity Health. 2016 Oct 10;15(1):168.

5. Shommu NS, Ahmed S, Rumana N, Barron GRS, McBrien KA, Turin TC. What is the scope of improving immigrant and ethnic minority healthcare using community navigators: A systematic scoping review. Int J Equity Health. 2016 Jan 15;15:6.

6. Bellefontaine T, Wisener R, Canada, Policy Horizons Canada. The evaluation of place-based approaches: questions for further research [Internet]. Ottawa, Ont.: Policy Horizons Canada; 2011 [cited 2017 Feb 21]. Available from: http://www.deslibris.ca/ID/229337

7. Charlebois K, Loignon C, Boudreault-Fournier A, Dupéré S, Grabovschi C. [The involvement of vulnerable people in participatory research in primary care: a literature review]. Glob Health Promot. 2014 Sep;21(3):38-45.

8. Boisvert R, Lafrance L, Grenier GW, Agence de la santé et des services sociaux de la Mauricie et du Centre-du-Québec, Direction de santé publique. Les inégalités sociales de santé ne sont pas une fatalité voyons-y!: rapport du directeur de santé publique sur les inégalités sociales de santé en Mauricie et au 
Centre-du-Québec [Internet]. Trois-Rivières: Agence de la santé et des services sociaux de la Mauricie et du Centre-du-Québec, Direction de santé publique; 2012 [cited 2017 Feb 21]. Available from: http://collections.banq.qc.ca/ark:/52327/2160894

9. S.-R Hyppolite. Comprendre et agir autrement pour viser l'équité en santé dans la région de la Capitale-Nationale. Québec: Agence de la santé et des services sociaux de la Capitale-Nationale; 2012 p. 164.

10. MF Le Blanc, MF Raynault, R Lessard. Les inégalités sociales de santé à Montréal: le chemin parcouru. Montréal: Agence de la santé et des services sociaux de Montréal; 2012.

11. Commission des Déterminants Sociaux de la Santé. Combler le fossé en une génération: instaurer l'équité en santé en agissant sur les déterminants sociaux de la santé. Organisation mondiale de la Santé; 2008.

12. Potvin L, Moquet M-J, Jones CM. Réduire les inégalités sociales en santé. Saint-Denis [Seine-SaintDenis: Inpes; 2010.

13. Santé Canada. Certaines circonstances: équité et sensibilisation du système de soins de santé quant aux besoins des populations minoritaires et marginalisées. Ottawa; 2001.

14. Frohlich KL, Potvin L. Transcending the known in public health practice: the inequality paradox: the population approach and vulnerable populations. Am J Public Health. 2008 Feb;98(2):216-21.

15. Link BG, Phelan J. Social conditions as fundamental causes of disease. J Health Soc Behav. 1995;Spec No:80-94.

16. Ministère de l'immigration, de la diversité et de l'inclusion. L'immigration permanente au Québec selon les catégories d'immigration et quelques composantes. Québec: Gouvernement du Québec, Direction de la recherche et de l'analyse prospective; 2011 p. 100.

17. Marie Munoz, Juan Carlos Chirgwin. Les immigrants et les demandeurs d'asile: nouveaux défis. Le Médecin du Québec. 2007 février;42(2):33-44.

18. Miszkurka M, Goulet L, Zunzunegui MV. Contributions of immigration to depressive symptoms among pregnant women in Canada. Can J Public Health Rev Can Sante Publique. 2010 Oct;101(5):35864.

19. Lassetter $\mathrm{JH}$, Callister LC. The Impact of Migration on the Health of Voluntary Migrants in Western Societies: A Review of the Literature. J Transcult Nurs. 2009 Jan;20(1):93-104.

20. Rousseau C, ter Kuile S, Munoz M, Nadeau L, Ouimet M-J, Kirmayer L, et al. Health care access for refugees and immigrants with precarious status: public health and human right challenges. Can J Public Health Rev Can Sante Publique. 2008 Aug;99(4):290-2. 
21. G Baron, N Stronach, M Roy. Mieux répondre aux besoins des communautés linguistiques et culturelles. Sherbrooke: Centre intégré universitaire de santé et de services sociaux de l'Estrie-Centre hospitalier universitaire de Sherbrooke, Direction de santé publique; 2016 p. 77.

22. Pottie K, Greenaway C, Feightner J, Welch V, Swinkels H, Rashid M, et al. Evidence-based clinical guidelines for immigrants and refugees. CMAJ Can Med Assoc J J Assoc Medicale Can. 2011 Sep 6;183(12):E824-925.

23. Pineault R, Équipe santé des populations et services de santé (Québec), Hôpital Charles-LeMoyne, Centre de recherche, Instituts de recherche en santé du Canada, Fondation canadienne de la recherche sur les services de santé. L'accessibilité et la continuité des services de santé: une étude sur la première ligne au Québec [Internet]. Longueuil]; Montréal: Centre de recherche de l'Hôpital Charles LeMoyne; Agence de la santé et des services sociaux de Montréal : Institut national de santé publique du Québec; 2009 [cited 2017 Mar 22]. Available from: http://collections.banq.qc.ca/ark:/52327/1870263

24. Tremblay M-Ė, Dubé-Linteau A, Institut de la statistique du Québec. Enquête québécoise sur l'expérience de soins 2010-2011. [Internet]. 2013 [cited 2017 Feb 21]. Available from: http://collections.banq.qc.ca/ark:/52327/2275673

25. KB Newbold, J Cho, M McKeary. Access to Health Care: The Experiences of Ref-ugee and Refugee Claimant Women in Hamilton, Ontario. Journal of Immigrant \& Refugee Studies. 2013;11(4):431-49.

26. G Baron, M Roy, N Stronach. Mieux répondre aux besoins des communautés linguistiques et culturelles de l'Estrie. Sherbrooke: Centre intégré universitaire de santé et de services sociaux de l'Estrie Centre hospitalier universitaire de Sherbrooke, Direction de santé publique; 2016 p. 67. (Rapports de la directrice de santé publique).

27. Grabovschi C, Loignon C, Fortin M. Mapping the concept of vulnerability related to health care disparities: a scoping review. BMC Health Serv Res. 2013 Mar 12;13:94.

28. P Lombrail. Accès aux soins. In: Les inégalités sociales de santé. Paris: La découverte; 2000.

29. Asanin J, Wilson K. "I spent nine years looking for a doctor": exploring access to health care among immigrants in Mississauga, Ontario, Canada. Soc Sci Med 1982. 2008 Mar;66(6):1271-83.

30. Bedos C, Brodeur J-M, Benigeri M, Olivier M. [Social inequalities in the demand for dental care]. Rev Epidemiol Sante Publique. 2004 Jun;52(3):261-70.

31. M Gauthier, AA Lacasse, M Girard. Portrait et étude des besoins d'accompagnement de jeunes adultes dans les arrondissements La Cité-Limoilou et Les Rivières de la ville de Québec. Québec: Institut national de la recherche scientifique, Centre Urbanisation Culture Société, Observatoire Jeunes et Société; 2011. 
32. Brabant Z, Raynault M-F. Health of migrants with precarious status: results of an exploratory study in Montreal--Part B. Soc Work Public Health. 2012;27(5):469-81.

33. C McAll, J Fortier, PJ Ulysse, R Bourque. Se libérer du regard, Agir sur les barrières: points de vue sur la pauvreté à Montréal. Montréal: Université de Montréal; 2000.

34. Wolff H, Stalder H, Epiney M, Walder A, Irion O, Morabia A. Health care and illegality: a survey of undocumented pregnant immigrants in Geneva. Soc Sci Med 1982. 2005 May;60(9):2149-54.

35. LT Auger, L Nadeau, M Beauregard. Ces enfants venus d'ailleurs. Le Médecin du Québec. 2007;42(3):55-63.

36. P Bernard, M Raynault. Inégalités sociales de santé: feux, contre-feux et piliers de bien-être. Santé. Société et Solidarité: revue de l'observatoire franco-québécois de la santé et de la solidarité. 2004;2:4958.

37. A Couffinhal, $P$ Dourgnon, $P$ Geoffard, $M$ Grignon, $M$ Jusot, $J$ Lavis. Politiques de réduction des inégalités de santé, quelle place pour le système de santé? Un éclairage européen. Première partie: les déterminants des inégalités sociales de santé et le rôle du système de santé. Inst Rech Doc En Économie Santé. 92(Février):1-6.

38. Wu Z, Penning MJ, Schimmele CM. Immigrant status and unmet health care needs. Can J Public Health Rev Can Sante Publique. 2005 Oct;96(5):369-73.

39. Thomson MS, Chaze F, George U, Guruge S. Improving Immigrant Populations' Access to Mental Health Services in Canada: A Review of Barriers and Recommendations. J Immigr Minor Health. 2015 Dec;17(6):1895-905.

40. Bhatia R, Wallace P. Experiences of refugees and asylum seekers in general practice: a qualitative study. BMC Fam Pract. 2007 Aug 21;8:48.

41. Louise Tremblay. La discrimination dans le domaine de la santé: mieux les comprendre pour mieux les combattre. Cent Santé Serv Sociaux Mont. 2011 Sep 7;2(7):1-4.

42. Ocean C, WISE Society (B.C.). Policies of exclusion, poverty, and health: stories from the front. Duncan, BC: WISE Society; 2005.

43. Stewart M, Reutter L, Makwarimba E, Rootman I, Williamson D, Raine K, et al. Determinants of health-service use by low-income people. Can J Nurs Res Rev Can Rech En Sci Infirm. 2005 Sep;37(3):104-31.

44. Loignon C, Hudon C, Goulet É, Boyer S, De Laat M, Fournier N, et al. Perceived barriers to healthcare for persons living in poverty in Quebec, Canada: the EQUlhealThY project. Int $\mathrm{J}$ Equity Health. 2015 Jan 17;14:4. 
45. Conference of Deputy Ministers of Health (Canada), Federal/Provincial/Territorial Advisory Committee on Population Health and Health Security, Health Disparities Task Group, Public Health Agency of Canada. Reducing health disparities: roles of the health sector: discussion paper [Internet]. Ottawa, Ont.: Public Health Agency of Canada; 2005 [cited 2017 Feb 21]. Available from: http://www.deslibris.ca/ID/205187

46. Williamson DL, Stewart MJ, Hayward K, Letourneau N, Makwarimba E, Masuda J, et al. Lowincome Canadians' experiences with health-related services: implications for health care reform. Health Policy Amst Neth. 2006 Mar;76(1):106-21.

47. Organisation Mondiale de la Santé. Migration et santé [Internet]. Available from: www.euro.who.int/en/health-topics/health-determinants/migration-and-health

48. Québec (Province), Ministère de la santé et des services sociaux, Direction des communications, Bibliothèque numérique canadienne (Firme). Plan stratégique du ministère de la Santé et des Services sociaux du Québec 2015-2020. [Internet]. 2016 [cited 2017 Feb 21]. Available from: http://www.deslibris.ca/ID/10049423

49. Conference of Deputy Ministers of Health (Canada), Federal/Provincial/Territorial Advisory Committee on Population Health and Health Security, Health Disparities Task Group, Public Health Agency of Canada. Reducing health disparities: roles of the health sector: discussion paper [Internet]. Ottawa, Ont.: Public Health Agency of Canada; 2005 [cited 2017 Apr 4]. Available from: http://www.deslibris.ca/ID/205187

50. Public Health Agency of Canada, Boyd R, Marshall H. L'administrateur en chef de la santé publique rapport sur l'état de la santé publique au Canada, 2008 [Internet]. Ottawa, Ont.: Agence de santé publique du Canada; 2008 [cited 2017 Apr 4]. Available from: http://site.ebrary.com/id/10248802

51. P Lombrail, Marie-José Moquet. Rôle des soins dans les stratégies de réduction des inégalités sociales de santé. In: Réduire les inégalités sociales en santé. Saint-Denis [Seine-Saint-Denis: Inpes; 2010.

52. L Maillet, P Lamarche, B Roy, M Lemire. Adapting actors and interactions in primary care with respect to migrant patients. Journal of Organizational Change and Management.

53. Ministère de la Santé et des Services socaiux. Une passerelle vers un avenir en santé: La planification et l'organisation des services à l'intention des réfugiés et des demandeurs d'asile: évaluer le bien-être et l'état de santé physique pour mieux desservir- Orientations ministérielle. Sherbrooke: Gouvernement du Québec; 2012.

54. CIUSSS de l'Estrie-CHUS. Cliniques des réfugiés [Internet]. 2017. Available from: http://www.santeestrie.qc.ca/trouver-un-point-de-service/cliniques-specialisees/clinique-des-refugies/ 
55. Québec (Province), Ministère de la santé et des services sociaux, Québec (Province), Direction générale des services sociaux, Direction des services généraux. Les services généraux offerts par les centres de santé et de services sociaux [Internet]. Québec: Santé et services sociaux Québec, Direction générale des services sociaux, Direction des services généraux; 2004 [cited 2017 Apr 4]. Available from: http://www4.bnquebec.ca/pgq/2005/2914806.pdf

56. Zulma Erika Sotomayor Alvarez. Les Besoins en santé physique et mentale des réfugiés. Sherbrooke: Université de Sherbrooke; 2016 p. 18.

57. Québec (Province), Ministère de la santé et des services sociaux, Direction générale de la planification stratégique évaluation et de la gestion de l'information. L'intégration des services de santé et des services sociaux le projet organisationnel et clinique et les balises associées à la mise en oeuvre des réseaux locaux de services de santé et de services sociaux. [Internet]. Québec: Le Ministère, Direction des communications; 2004 [cited 2017 Apr 4]. Available from: http://bibvir.uqac.ca/bd/man.php? TD $=$ ARC\&IdNot $=18368870 \&$ FORMAT $=p d f$

58. Graham ID, Logan J. Innovations in knowledge transfer and continuity of care. Can J Nurs Res Rev Can Rech En Sci Infirm. 2004 Jun;36(2):89-103.

59. Pineault, R, Levesque, J-F, Tousignant, P, Beaulne, G, Hamel, M, Poirier, L-R, et al. L'accessibilité et la continuité dans la population: l'influence des modèles d'organisation des services de santé de première ligne. 2004;

60. Haggerty J, Burge F, Lévesque J-F, Gass D, Pineault R, Beaulieu M-D, et al. Operational definitions of attributes of primary health care: consensus among Canadian experts. Ann Fam Med. 2007 Aug;5(4):336-44.

61. Reid, R, Haggerty, J, McKendry, R. Defusing the confusion: concepts and measures of continuity of healthcare. Can Health Serv Res Found. 2002;

62. Murray CJ, Frenk J. A framework for assessing the performance of health systems. Bull World Health Organ. 2000;78(6):717-31.

63. Starfield B. Primary care in Canada: coming or going? Healthc Pap. 2008;8(2):58-62; discussion 64-67.

64. Lavoie C, Joncas J-A. Le dessin-entretien: un outil de collecte de données innovateur et approprié auprès des communautés culturelles et linguistiques minoritaires. Rech Qulitatives. 2015;34(1):97, page 112.

65. CSSS-IUGS. Intervention de quartiers. 2017.

66. Paul Morin, Maryse Benoît, Nicole Dallaire, Chantal Doré, Jeannette LeBlanc. L'intervention de quartier à Sherbrooke, ou quand le CLSC s'installe à la porte d'à côté. Nouvelles pratiques sociales. 
2013;26(1):102-17.

67. Observatoire estrien du développement des communautés. Ville de Sherbrooke, Communauté locale «Des Jardins-Fleuris». Observatoire estrien du développement des communautés. 2011.

68. $\mathrm{CH}$ Weiss. Research for policy's sake: The enlightenment function of social research. Policy analysis. 1977;531-45.

69. Maillet L, Lamarche P, Roy B, Lemire M. At the heart of adapting healthcare organizations: Developing a multilevel governance framework. Emergence Complex Organiztion. 2015;17(3).

\section{Declarations}

- Ethics approval and consent to participate: This study was approved by the Comité d'éthique de la recherche du CIUSSS de l'Estrie - Centre hospitalier universitaire de Sherbrooke (\#2018-2384).

- Consent for publication: Not applicable

- Availability of data and material: The datasets used will be available from the corresponding author on reasonable request.

- Competing interests: The authors declare that they have no competing interests

- Funding statement: This work was supported by Reseau 1 Québec (2017-2019).

- Authors' contributions: All authors agreed on the publication of this protocol paper. LM and LMM prepared and edited the paper. All the co-authors participated in writing the protocol. They also read and approved the final version of this manuscript.

- Acknowledgments: We would like to thank all co-researchers, users, and health professionals with lived experience from the community for their invaluable involvement in the success of this project. We would like to thank Arthur Durieux for his assistance in providing translation and language editing services. 